\title{
Sequential Analysis of the Social Play of Young Children With Mild Developmental Delays
}

\section{MICHAEL J. GURALNICK \& MARY A. HAMMOND}

University of Washington

This study examined the sequential process of. social participation with peers for young children with mild developmental delavs. Based on measures of sequential dependency. comparisons were made between children with and without developmental delays and across specialized and inclusive settings. The identification of probable and improbable paths from one play state to another also was determined. Results revealed the existence of highly similar sequential play patterns between children with and without mild developmental delays and across settings. The implications of these findings for intervention and the importance of the intrinsic organization of sequential play processes were discussed.

The unusual difficulties encountered by young children with developmental problems in establishing social relationships with their peers have now been well documented (Guralnick. 1990b: Odom. McConnell. \& McEvoy, 1992). For children with general (cognitive) developmental delays, even mild delays. the prevalence and severity of peer interaction problems may well place this group of children on a developmental trajectory leading to significant later life adjustment difficulties (Parker \& Asher. 1987) and to substantial levels of social isolation (Taylor, Asher, \& Williams, 1987; Williams \& Asher, 1992). These early peer interaction problems are especially evident when children with mild developmental delays participate in unstructured or free-play activities in playgroups or in preschool programs. In comparison to typically developing same chronological age children, preschoolage children with mild delays exhibit a pattern of less extensive and sustained interactive play with peers. and engage in substantial levels of solitary play (Guralnick, Connor, Hammond, Gottman, \& Kinnish, 1996; Guralnick \& Groom, 1987; Guralnick \& Weinhouse, 1984: Kopp. Baker. \& Brown, 1992). Many of these differences remain even when controlling for developmental level (Guralnick \& Groom, 1985, 1987).

Specific difficulties resolving conflicts, gaining entry into groups of children already engaged in play, directing others in play, and regulating emotions during child-child exchanges are factors likely to account for at least some proportion of this relative absence of social participation with peers (Guralnick \& Groom, 1987; Guralnick et al., 1998; Kopp et al., 1992). Although less well documented. contributing factors may include social information processing difficulties (Dodge, Pettit, McClaskey. \& Brown, 1986; Guralnick. 1992) and carty over effects from lack of experience due to more restricted peer social networks (Guralnick, 1997).

These comparisons between children with and without developmental delays have been instructive in identifying areas of concern and providing a framework for designing intervention programs. For the most part, however, the profile of differences has consisted primarily of summary or overall measures of children's social behavior with their peers. Yet, the process of social play is a dynamic and sequential 
one in which children move through various pathways from one play state to another. Analyses of these moment-to-moment transitions may yield insights into the more subtle processes through which children interact with their peers. and provide an alternative perspective on children's peer-related social competence. Accordingly, the general purpose of this investigation was to characterize this sequential process of social participation with peers for young children with mild developmental delays.

Although play states can be defined in many ways, perhaps the most well studied system is the play categories found in Parten's (1932) index of social participation. Primary social participation states include categories of onlooker and unoccupied behavior, as well as the categories of solitary, parallel, and group play. To be sure, concerns exist with regard to the presumed developmental sequence and hierarchical nature of the social participation scale (Bakeman \& Brownlee, 1980; Roper \& Hinde, 1978: Rubin, Maioni. \& Homung. 1976; Smith, 1978). The Parten scale or variations have yielded important information with respect to: (a) developmental changes over time (Barnes, 1971: Rubin \& Krasnor, 1980, Rubin, Watson, \& Jambor, 1978; Smith, 1978); (b) socioeconomic status (Rubin et al., 1976); (c) environmental conditions (Vandenberg, 1981): (d) the familiarity of peers (Doyle, Connolly, \& Rivest, 1980); (e) differences between mixed- and same-age groupings (Bailey, McWilliam, Ware, \& Burchinal. 1993: Goldman, 1981); (f) playmate preferences (Rubin, Lynch, Coplan, Rose-Krasnor, \& Booth. 1994); (g) distinctions among. various forms of social withdrawal (Coplan, Rubin, Fox, Calkins, \& Stewart, 1994); and (h) the psychobiology of children's social behavior (Fox. Schmidt, Calkins, Rubin, \& Coplan, 1996).

The sequential analysis of the pathways across different play states for typically developing children using a variation of Parten's (1932) scale carried out by Bakeman and Brownlee (1980) revealed a number of interesting findings. It was evident that children $(\mathrm{N}$ $=41$ ) moved frequently from one play state to another, but that certain transitions were more probable than others. Specifically, analyses of state based transitional probabilities indicated that children frequently shifted back and forth between states. and that highly probable paths included parallel to group play, unoccupied to solitary play, and solitary play to unoccupied. These investigators also identified a number of improbable transition paths including shifts from unoccupied to group play. from parallel play to unoccupied. and from group play to either unoccupied or solitary play. It appeared that children were organizing their play sequences in a manner that adds complexity (i.e., integrating play with objects in solitary play into a social play activity) but doing so repeatedly throughout the free-play sessions. The importance of using parallel play as a strategic means of moving to group play also was noted in that the only probable path to group play was via parallel play. Clearly, young typically developing children exhibit systematic sequences across play states within relatively brief time periods. Of note, these patterns were similar across a different, though relatively narrow, chronological age range.

Following a similar analytic approach in the present study, a sequential analysis of play state patterns comparing children with and without mild developmental delays was carried out as children interacted in a series of small playgroups. In addition to comparisons between groups, analyses focused on the identification of probable and improbable paths from one state to another. Typically developing children were matched carefully to children with mild developmental delays in both chronological age and family demographics.

Also addressed in this study was whether these sequential patterns were affected by the type of setting in which children interacted with one another. More specifically, it is quite possible that play state patterns exhibited by children with delays will differ as a consequence of the availability of socially interactive play partners. Especially in settings containing only other delayed children (specialized settings), the presence of less interactive and responsive playmates in these settings 
could easily foster a pattern of state-based transitions not found in settings containing more interactive typically developing children (inclusive settings). In particular. the social interaction levels of children with developmental delays and related disabilities do increase for the most part as a consequence of participation with typically developing children in inclusive settings (see Buysse \& Bailey. 1993). Moreover. it has been suggested that the presence of typically developing children in an inclusive setting provides an organizational framework for the social play of children with delays (Guralnick, et al.. 1996). In contrast. there is little reason to expect differences to occur, particularly disruptions, in play state patterns for typically developing children as a function of setting because no negative effects for typically developing children participating in inclusive settings have been detected (Buysse \& Bailey, 1993: Guralnick. 1990a). Nevertheless, since sequential play patterns have not previously been investigated in relation to type of setting, this possibility also was examined in this investigation. Of note, a chronological age match rather than a developmental level match was selected because similar chronological age groupings are most common in inclusive preschool settings. and parents of children with delays consider chronological agemates as the proper reference group for their children (Guralnick, Connor. \& Hammond, 199j).

\section{METHOD}

\section{Overview}

As part of a larger study (Guralnick et al., 1996). previously unacquainted groups of children were brought together to form a series of 12 separate playgroups ( $n=6$ children per playgroup). Of the 12 playgroups 6 were specialized: 3 consisting of only typically developing children and 3 consisting of only children with developmental. delays. The remaining 6 playgroups were inclusive, each consisting of 4 typically developing children and 2 children with developmental delays. As described later, a matching procedure ensured that typically developing children assigned to inclusive or specialized playgroups, as well as children with developmental delays assigned to inclusive or specialized playgroups, were equivalent within each of the two types of playgroups in terms of child characteristic measures (chronological age. cognition. language. adaptive behavior. and behavior problems). A similar matching also ensured equivalence across all groups for family demographic measures (family social status, marital status). For each 2-week playgroup. the social and play interactions of each child were recorded during a designated free-play period.

\section{Participants}

Typically developing children were recruited through direct contact with administrators and teachers of public and private nursery school and daycare programs. Children with developmental delays were recruited from community-based preschool programs and from rosters of children who received clinical evaluations from diagnostic clinics. The chronological age range for all subjects was established at 4 years 3 months to 5 years 6 months. Only boys were selected to participate in the playgroups because resources were not available to include gender as an additional independent variable, and more boys were available in community preschools. Similarly, to avoid potential confounds due to race, only Caucasian children were selected. In addition, children were excluded from participating for any of the following reasons: (a) three siblings within 3 years-of-age of the child being considered, (b) teacher reports of major disruptive behavior problems, (c) legally blind or major uncorrected hearing loss, (d) significant motor problems, (e) acquainted with other children in the playgroup. and ( $f$ ) living with the primary caregiver less than one year.

For selection and matching purposes, the Wechsler Preschool and Primary Scale of Intelligence (WPPSI-R; Wechsler, 1989) was administered individually to all prospective children. Full Scale IQ (FSIQ) scores, as well as performance (PIQ) and verbal (VIQ) scores were obtained. Two individually administered language tests also were used. First, the Test for Auditory Comprehension of Language 
(TACL-R: Carrow-Woolfolk, 1985), which consists of scales for word classes and relations, grammatical morphemes, and elaborated sentences, was used. A total score (standard score) was obtained. Second. to supplement the receptive language assessment of the TACL- $R$, we used the expressive components of the Preschool Language Scale (Zimmerman. Steiner. \& Pond. 1979). Because of the lack of standardization. only raw scores (range $0-48$ for verbal ability and $0-23$ for articulation) were used.

In addition to cognitive and language measures, mothers served as respondents for assessments of their child's adaptive behavior and behavior problems. First, the Vineland Adaptive Behavior Scales (Sparrow, Balla, \& Cicchetti. 1984) Survey Form was administered to mothers by trained interviewers. Standard scores were obtained for each of the four domains (communication, daily living skills, socialization, and motor skills), as well as for the total adaptive behavior score. Second, mothers' assessment of their child's behavior problems was obtained from the Child Behavior Checklist (CBCL; Achenbach \& Edelbrock. 1991). Mothers rated the frequency of different behavior problems from a 118 item questionnaire using a 3-point scale. Orily the broad band internalizing and externalizing scales ( $T$ scores) in.conjunction with a total behavior problem score were used for subject selection and matching purposes. Higher scores indicate greater perceived behavior problems. Finally, responses to a parent questionnaire provided basic demographic information. The Hollingshead Four Factor Index of Social Status (Hollingshead, 1975) was used to calculate a measure of family status (range 8-66).

Beyond the inclusionary and exclusionary criteria applied to all subjects noted earlier, specific criteria also were established for each of the two groups of children differing in developmental characteristics. Specifically, typically developing children were included if they achieved a FSIQ score between 90 and 130. Children were excluded, however, for any of the following reasons: (a) VIQ or PIQ lower than 90, (b) TACL-R total score less than 90, (c) CBCL Total Problem score greater than the 90 percentile. (d) enrolled in a preschool program in which more than $15 \%$ of the children have established disabilities. or (e) has a sibling with an established disability. Similarly, children with developmental delays were included if they achieved a FSIQ between 52 and 80 . Children in this group were excluded. however, for any of the following reasons: (a) PIQ greater than 90 . (b) $\mathrm{CBCL}$ total problem score greater than the 98th percentile or teacher reports of continuous and substantial disruption. and (c) a TACL-R total score less than 55 or greater than 90 .

\section{Matching Procedures}

First, children with developmental delays were identified for each playgroup. Then, to maximize similar demographic characteristics. typically developing children from the same neighborhood who were participating in both inclusive and specialized groups were recruited. Children were tested on a continuous basis across a 4-year period, and playgroups were formed when an appropriate number of children meeting criteria were recruited. Specialized and inclusive playgroups were interspersed over the 4 years. On occasion, a child meeting established criteria was not included if test scores were inconsistent with matching projections for the demographic and child characteristic measures.

As presented in Table 1, child characteristic measures were comparable for the typically developing children participating in the inclusive and specialized playgroups $(\mathrm{p}>.05$ ). The only exception was that typically developing children participating in specialized playgroups had a higher Vineland Daily Living Skills score than did typically developing children participating in the inclusive playgroups $(p<.05)$. Comparable scores also were obtained across all child characteristic measures for children with developmental delays participating in specialized and inclusive settings.

As expected, statistically significant differences were obtained for most of the child characteristic measures (see Table 1 for details) when comparing typically developing 
Table 1.

Child Characteristic Measures by Group and Setting

\begin{tabular}{|c|c|c|c|c|c|c|c|c|}
\hline \multirow[b]{3}{*}{ Child Characteristics } & \multicolumn{4}{|c|}{ Typically Developing } & \multicolumn{4}{|c|}{ Developmentally Delayed } \\
\hline & \multicolumn{2}{|c|}{$\begin{array}{l}\text { Specialized } \\
(n=18)\end{array}$} & \multicolumn{2}{|c|}{$\begin{array}{l}\text { Inclusive } \\
(n=24)\end{array}$} & \multicolumn{2}{|c|}{$\begin{array}{l}\text { Specialized } \\
(n=18)\end{array}$} & \multicolumn{2}{|c|}{$\begin{array}{l}\text { Inclusive } \\
(n=12)\end{array}$} \\
\hline & M & $(S D)$ & . & (SD) &.$M$ & $(S D)$ & .4 & $(S D)$ \\
\hline Chronolugical tge (months) & 56.28 & $13.51)$ & 57.25 & $(4.00)$ & 58.83 & $(4.90)$ & 57.50 & $(4.78)$ \\
\hline \multicolumn{9}{|l|}{ WPPSI-R } \\
\hline Full Scale [Q & 110.06 & (10.88) & L I I.83 & $(10.74)$ & 66.00 & 19.951 & 67.92 & (8.06) \\
\hline Performance $I^{-}$ & 110.83 & $(13.01)$ & 109.38 & $(10.59)$ & 68.00 & $(\lfloor 1.38)$ & 70.08 & $(8.12)$ \\
\hline Verbal IQ & 107.39 & $(12.19)$ & 110.42 & $(11.08)$ & 70.06 & (9.69) & 71.33 & $(9.28)$ \\
\hline Pertormance-Verbal IQ & 3.4 & $(16.83)$ & -1.04 & $(11.51)$ & -2.06 & $(10.71)$ & -1.25 & (9.79) \\
\hline Full Scale $\mathrm{MA}^{\perp}$ & 61.51 & $(7.18)$ & 63.38 & $(7.89)$ & 38.22 & (6.93) & 38.80 & $(5.91)$ \\
\hline Performance $\mathrm{MA}^{\lrcorner}$ & 61.93 & $(8.19)$ & 62.23 & $(7.50)$ & 39.44 & $(7.75)$ & 40.08 & $(6.43)$ \\
\hline Verbal MA' & 60.03 & $(7.84)$ & 62.84 & $(8.05)$ & 40.51. & (6.70). & 40.68 & $(6.08)$ \\
\hline \multicolumn{9}{|l|}{ TACL-R } \\
\hline Total Scale & 105.06 & (7.05) & 109.21 & $(9.74)$ & 75.33 & $(9.64)$ & 73.00 & $(11.17)$ \\
\hline Word Class \& Relations & 106.33 & (9.25) & 110.63 & $(12.05)$ & 76.44 & $(18.74)$ & 80.17 & $(10.52)$ \\
\hline Grammatic Morphemes ${ }^{\star}$ & 103.06 & $(9.73)$ & 105.29 & $(10.65)$ & 78.22 & $(9.06)$ & 71.42 & $(1+.+2)$ \\
\hline Elaborated Sentences ${ }^{\wedge}$ & 105.06 & $(13.48)$ & 109.83 & ( 10.89$)$ & 82.89 & $(8.07)$ & 80.75 & $(11.31)$ \\
\hline \multicolumn{9}{|l|}{ PLS } \\
\hline Verbal Ability ${ }^{2}$ & 35.83 & $(4.97)$ & 37.33 & $(4.17)$ & 19.11 & $(9.00)$ & 21.83 & (7.30) \\
\hline Articulation & 19.83 & $(2.29)$ & 21.00 & $(2.60)$ & 12.83 & (6.38) & 15.60 & (5.32) \\
\hline \multicolumn{9}{|l|}{ Vineland } \\
\hline Total Adaptive Behavior & 97.56 & $(11.12)$ & 92.25 & $(10.11)$ & 67.56 & $(7.90)$ & 70.25 & $(9.27)$ \\
\hline Communication $^{\lrcorner}$ & 96.00 & $(9.76)$ & 96.50 & $(7.99)$ & 77.00 & $(12.50)$ & 76.17 & $(11.56)$ \\
\hline Daily Living Skills ${ }^{\lrcorner}$ & 97.61 & $(11.06)$ & 88.38 & $(10.95)$ & 70.11 & (6.93) & 74.00 & $(12.47)$ \\
\hline Socialization ${ }^{\lrcorner}$ & 99.39 & $(8.53)$ & 98.63 & $(10.40)$ & 78.67 & $(9.13)$ & 81.33 & (12.69) \\
\hline Motor Skills & 100.83 & $(9.65)$ & 94.83 & $(14.76)$ & 64.67 & $(1+.22)$ & 70.83 & (13.30) \\
\hline \multicolumn{9}{|l|}{$\mathrm{CBCL}$} \\
\hline Total Behavior Problems & 46.61 & $(7.82)$ & 47.83 & $(8.00)$ & 55.11 & $(8.79)$ & 52.42 & $(10.08)$ \\
\hline Extemalizing & 48.61 & $(8.42)$ & 48.13 & $(9.83)$ & 50.44 & $(10.55)$ & 49.58 & $(12.41)$ \\
\hline Internalizing & 46.00 & $(9.31)$ & 48.21 & $(7.57)$ & 57.94 & $(10.06)$ & 53.50 & $(6.92)$ \\
\hline
\end{tabular}

Vole. WPPSI-R = Wechsler Preschool and Primary Scale of Intelligence-Revised: VIQ = verbal IQ: PIQ = performance IQ: FSIQ = Full-Scale IQ: TACL-R = Test of Auditory Comprehension-Revised: PLS = Preschool Language Scale: VABS = Vineland Adaptive Behavior Scales: $\mathrm{CBCL}=$ Child Behavior Checklist.

Indicates a vignificant difference $(p<.05)$ between typically developing children and children with developmental delays.

children and children with developmental delays. The exceptions were child's chronological age, the PIQ-VIQ discrepancy, and the CBCL externalizing factor $(p>.05)$. Finally, for family demographics, $91.7 \%$ of the mothers were partnered, with an average family social strata based on the Hollingshead index of 2.15 (medium business. minor professional). The four groups did not differ for these two family demographic measures $\left(\chi^{2}\right.$ and Krus-
kall-Wallace one-way ANOVA, respectively, $\mathrm{p}>.05$ )

\section{Playgroup Setting and Procedure}

Each six-child playgroup operated 2-1/2 hours per day, 5 days per week, for 2 weeks ( 10 sessions) in either a morning or afternoon time period. Children arrived in separate vehicles (via parents or drivers), and parents were asked to avoid contact with the other families 
or children for the duration of the playgroup. Parents were paid $\$ 100$ plus transportation expenses.

Playgroups were supervised by a teacher and graduate assistant in a specially designed laboratory playroom (approximately 375 square feet). Children participated in a series of group and individual activities typical of preschool programs. including circle time. music. art. snack, and story. During two daily 30-minute free play periods. children had access to the extensive array of toys and equipment found in the playroom. Separate areas provided opportunities for housekeeping, blocks, puzzles, games, and precast and manipulative toy play activities, as well as an option for individual reading. Although the teacher generally encouraged social and play interactions among the children in other activities, during free- play periods the teacher limited her interactions to providing assistance when necessary.

Using split-screen technology, children's social and play interactions were videorecorded by two remote controlled cameras mounted at either end of the playroom and a hand-operated camera in an adjacent observation room. The child being recorded at the time (focal child) wore a specially designed lightweight vest equipped with a professional quality wireless microphone and transmitter secured in a hidden pocket in the back of the vest. Other microphones were placed discreetly throughout the room and a control panel of mixers balanced the auditory signals.

Each child was observed for a total of 60 minutes during free play over the 2 -week period. Recording commenced on the second playgroup day and was divided into segments of 10 consecutive minutes for each of 6 recording periods per child. The order of recording children was randomized within blocks of six 10-minute segments, and no child was observed more than once per day. In addition. recordings were distributed such that each child was videotaped on three occasions within the first week and on three occasions during the second week.

\section{Measure of Social Participation}

A slightly modified version of the scale developed by Rubin (1985), based on Parten's (1932) index of social participation. formed the basis for characterizing children's play states. A time code superimposed on each videotape, in conjunction with a remotely controlled tape-stop device. allowed observers to view tapes at 10 -second intervals. Coders recorded the categories of social participation (level of cognitive play not considered here) during each 10-second interval. The coding of each 10-second interval represented a particular play state. The scale consists of the following 10 mutually exclusive and exhaustive categories: (a) unoccupied behavior (child not playing), (b) onlooker behavior (child watches other children but does not enter into play). (c) solitary (playing alone), (d) parallel (playing next to another child). (e) group (playing with another child; a combination of Parten's associative and cooperative play categories). (f) reading or listening (reading. leafing through a book, listening to a tape), (g) exploration (examining physical properties of objects), (h) active conversation (talking. questioning, and suggesting to other children but not playing), (i) transition (moving from one activity to another), and ( $\mathrm{j}$ ) adult-directed (any activity with an adult). The category that dominated the interval (time based) was coded if more than one type of play occurred.

These categories were reduced to the following seven measures: (a) unoccupied. (b) onlooker, (c) solitary (included reading and exploration), (d) transition, (e) parallel, (f) group, and ( $g$ ) conversation. As a consequence, 42 transitions were possible from one play state to another. A category referred to as "other." consisting of adult-directed and non-codeable intervals, was also established, but not included in the analysis because it occurred in less than $4 \%$ of the intervals.

Reliability. Prior to coding, five raters were trained for a period of 12-19 weeks. Videotapes of pilot playgroups were used for training and final prestudy reliability assessments. All raters met the minimum established criterion of $70 \%$ interobserver agreement for each major category on ten 10-minute seg- 
ments from a reliability tape containing complex segments. Reliability also was obtained for each rater during the study for $25 \%$ of the playgroup tapes selected randomly but balanced to ensure representation from the two types of settings, groups, and time.

Point-to-point reliability was based on percent agreement obtained across all of the 10second observation intervals (number of agreements divided by the total number of observations and transformed to a percentage). Cohen's (1960) kappa also was calculated where appropriate. For prestudy reliability, raters agreed on a mean of $84 \%$ (range $83 \%$ $85 \%$ ) of the intervals (kappa $=.80$ ) for the categories of the social participation scale. During the course of the study, average interobserver agreement continued to be high in all instances for each of the social participation categories: mean $=86 \%$ (range $82 \%-$ $90 \%), \mathrm{kappa}=.82($ range $.71-.92)$.

Reliability also was determined for the sequential dependency measure. Specifically, following the recommendation of Bakeman. Quera, McArthur, and Robinson (1997), the sequential dependency index. Yule's $Q$ (see below). for transitions between different play states (state-based transitions), was calculated for the same $25 \%$ of sessions (107 total sessions) for each of two independent coders. Intraclass correlation coefficients were then calculated for each of the 42 possible state-based transitions to estimate interobserver agreement for the sequential dependency index. The mean intraclass coefficient was .65 (SD $=.12$; range $=.30-.92$ ). Only 3 of the 42 values fell below .50 and only 12 were below 60. Of note, because some transitions occurred infrequently, the interobserver agreement sessions upon which the intraclass correlation was based (maximum $=107$ ) varied accordingly.

\section{RESULTS}

Specific analyses focused on the number of transitions to a different play state, the probability of remaining in the same state across two adjacent intervals, and transitions between different but adjacent states (lag 1 prob- abilities; 42 possible transitions). The index of sequential dependency selected was Yule's $Q$. This measure ranges from - I (less than expected value) to +1 (greater than expected value). with zero indicating no effects considering chance rates. As indicated by Bakeman and his colleagues (Bakeman. in press; Bakeman. McArthur. \& Quera. 1996). Yule's Q measures the strength of an association and is most appropriate for parametric analyses of group differences. Additional analyses identified improbable and probable paths from one state to another.

Number of transitions and probability of remaining in the same play state. For these two measures, separate 2 (group) $\chi^{2}$ (setting) ANOVAs were conducted. For the number of transitions, no significant group, setting, or interaction effects were obtained ( $p>.05$ ). In general, children with and without developmental delays appeared to be active to a similar extent in shifting from one play state to another during free-play $(M=111.7$ and 124.7, respectively).

The second analysis reflected the extent to which children were likely to sustain at least short-term involvement in a specific form of social participation. Table 2 presents Yule's Q values for each play state code given the previous interval was the same code for each group summed across settings. All cases did not have Yule's Q scores for all 7 play category transitions. Specifically, one child with developmental delays had no instances of conversation and four children had no group play. Consequently, group-by-setting ANOVAs were carried out separately for each of the 7 categories, and alpha was set at .007 (Bonferroni correction). Analyses indicated a statistically significant main effect for parallel play between groups, $F(1,68)=9.98, \mathrm{p}=.002$. As noted in Table 2, typically developing children were less likely to remain engaged in parallel play than were children with developmental delays. Interestingly, both groups of children tended to remain in the same state to a substantial degree when engaged in solitary, parallel, or group play (approximately $2 / 3$ of the time). All other play states were far less stable, as children shifted frequently to anoth- 
Table 2.

Yule's $Q$ Scores for Each State When Previous Interval was Same State Summed Across Settings

\begin{tabular}{|c|c|c|c|c|}
\hline \multirow[b]{2}{*}{ Category } & \multicolumn{2}{|c|}{$\begin{array}{c}\text { Typically } \\
\text { Developing }\end{array}$} & \multicolumn{2}{|c|}{$\begin{array}{l}\text { Develop- } \\
\text { mentally } \\
\text { Delayed }\end{array}$} \\
\hline & .4 & $S D$ & . & $S D$ \\
\hline Lnoccupied & 60 & .67 & .54 & .71 \\
\hline Solitary & 88 & .06 & .89 & .06 \\
\hline Onlooker & 69 & +1 & 62 & .56 \\
\hline Transition & 58 & .67 & .65 & .57 \\
\hline Parallel Play & 89 & .06 & .94 & .06 \\
\hline Conversation & .78 & .30 & .1 & .81 \\
\hline Group Play & .91 & .30 & .82 & .54 \\
\hline
\end{tabular}

Vote. $n=42$ for typically developing. $n=30$ for developmentally delayed except for conversations $(n=29)$ and group play $(n=26)$

er state across adjacent intervals. A statistically significant interaction also was obtained for unoccupied play, $F(1.68)=8.38 . \mathrm{p}$ $=.005$. Follow-up t-tests indicated that children with delays remained in unoccupied play more often in the specialized than the inclusive setting, $t(28)=2.10, p=.045$. It is the similarity of sequential patterns between groups and across settings, however, that is most notable, especially given that the proportion of time children spend in these play states (summary measure) differs substantially as a function of both of these factors (e.g., Guralnick et al., 1996).

Sequential dependencies between different states. Table 3 presents Yule's Q scores for transitions between play states when the play state changed, summed across settings. Again, because all cases did not have Yule's $Q$ scores for all 42 transitions, group $x$ setting ANOVAs were run for each of the transitions separately and alpha was set at .001 (Bonferroni correction). None of the effects were statistically significant $(p>.001)$. Establishing alpha at .01 as an indicator of a trend, only three group comparisons (parallel given unoccupied; conversation given parallel; conversation given group), one setting (conversation given onlooker) and one interaction (solitary given conversation) were significant. In view of the large number of comparisons and the absence of obviously meaningful patterns of differences, the primary conclusion is that neither group nor type of setting affected sequential play patterns.

Probable and improbable paths. In this analysis, we attempted to obtain an alternative perspective on the comparison between groups and to gain a sense for patterns within groups. Specifically. summed over settings. the percentages of children in each group whose Yule's $Q$ was greater than 0 were calculated for each cell of the matrix representing transitions between different states. Following Bakeman's (in press) suggestion. and consistent with the Bakeman and Brownlee (1980) identification of probable and improbable paths, a sign test for each cell was conducted. Table 4 presents the results of these analyses. Probable paths between different states are indicated by a " $p$ " (percentage higher than chance) and improbable paths by an " $i$ " (percentage lower than chance). With the Bonferroni correction, alpha was set at $p=.001$. although results that were statistically significant at alpha $=.01$ are also presented in the table to indicate trends.

Consistent with the previous analysis. most evident are the similarities between groups. For typically developing children, the only probable path to group play is from parallel play. For children with delays, however, there is no probable path, as defined here, to parallel play although, as Table 4 suggests, parallel play is the most common state preceding group play (Yule's $Q$ greater than zero for $65 \%$ of children). In contrast to parallel play, unoccupied and transition states are improbable paths to group play for both groups of children.

For parallel play, the primary paths are from solitary play and onlooker play states for typically developing children. A similar pattern can be seen for children with delays, although onlooker play is not a probable path for these children. An unoccupied state is an improbable path for both groups. Interestingly, a reciprocal relationship between parallel and solitary play states is evident in that the most probable path to solitary play is from 
Table 3.

Yule's $Q$ Scores for Transitions Between States When Play State Changed

\begin{tabular}{|c|c|c|c|c|c|c|c|}
\hline \multirow{2}{*}{$\begin{array}{l}\text { GIVEN } \\
\text { STATE }\end{array}$} & \multicolumn{7}{|c|}{ TARGE'T STATE } \\
\hline & Ùnoccupied & Solitary & Onlooker & Transition & Parallel Play & Conversilion & Group Play \\
\hline \multicolumn{8}{|c|}{ Typically Developing } \\
\hline Solitary & $.10(.51)$ & & $.06(.43)$ & $.06(.57)$ & $.42(.24)$ & $.06(.30)$ & $-.07(.49)$ \\
\hline Onlooker & $-.06(.71)$ & $-.04(.41)$ & & $-.37(.67)$ & $.19(.35)$ & $-.02(.49)$ & $-.25(.61)$ \\
\hline Transition & $-.39(.71)$ & $.26(.43)$ & $-.49(.61)$ & & $-.34(.55)$ & $-.15(.64)$ & $-82(.43)$ \\
\hline Parallel Play & $-.33(.59)$ & $.39(.29)$ & $.04(.46)$ & $-.50(.54)$ & & $.12(.39)$ & $.36(.43)$ \\
\hline \multicolumn{8}{|c|}{ Note. Mean values of Yule's $Q$ are labled with standard deviations in parentheses. $n=42$. } \\
\hline \multicolumn{8}{|c|}{ Developmentally Delayed } \\
\hline Unoccupied & & $.10(.51)$ & $-.09(.67)$ & $.07(.68)$ & $-.68(.46)$ & $-.33(.79)$ & $-.73(.53)$ \\
\hline Solitary & $.15(.52)$ & 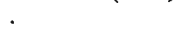 & $.16(.54)$ & $.14(.50)$ & $.38(.50)$ & $-.08(.01)$ & $-.03(.61)$ \\
\hline Onlooker & $.14(.57)$ & $.19(.46)$ & & $-.42(.56)$ & $.01(.56)$ & $-.2+(.67)$ & $-.48(.63)$ \\
\hline
\end{tabular}

Note. Mean values of Yule's $Q$ are tabled with standard deviations in parentheses.

$n=30$ except for transitions involving conversation $(n=29)$ and transitions involving group play $(n=26)$. 
Table 4.

Percentage of Children for Whom Yule's Q Scores for Transition Between Different States Were Above Zero

\begin{tabular}{|c|c|c|c|c|c|c|c|}
\hline \multirow[b]{2}{*}{$\begin{array}{l}\text { GIVEN } \\
\text { STATE }\end{array}$} & \multicolumn{7}{|c|}{ TARGET STATE } \\
\hline & Unoccupied & Solitary & Onlooker & Transition & $\begin{array}{c}\text { Parallel } \\
\text { Play }\end{array}$ & $\begin{array}{c}\text { Conver- } \\
\text { sation }\end{array}$ & $\begin{array}{c}\text { Group } \\
\text { Play }\end{array}$ \\
\hline \multicolumn{8}{|c|}{ Typically Developing } \\
\hline L'noccupied & & 64 & 43 & 67 & $29 * i$ & +5 & $12 * * i$ \\
\hline Solitary Play & $71 * p$ & & 62 & 57 & $98^{* *} p$ & 55 & +5 \\
\hline Onlooker & $57^{\circ}$ & 52 & & 38 & $74^{*} p$ & 62 & 45 \\
\hline Transition & 38 & $79^{* *} \mathrm{p}$ & 31 & & 33 & 52 & $07^{* * i}$ \\
\hline Parallel Play & 36 & $90^{* *} \mathrm{p}$ & 50 & $21^{* * i}$ & & 67 & $88^{* *} \mathrm{p}$ \\
\hline Conversation & 52 & 60 & 62 & 57 & 67 & & 40 \\
\hline Group Play & $21 * * i$ & 52 & 38 & $14 * * \mathrm{i}$ & 62 & $6 ?$ & \\
\hline
\end{tabular}

Vore. $\mathrm{p}=$ probable transition: $\mathrm{i}=$ improbable transition. $\ldots$ $n=+2$.

${ }^{*} p<.01 * * p<.001$.

\begin{tabular}{|c|c|c|c|c|c|c|c|}
\hline \multicolumn{8}{|c|}{ Developmentally Delayed } \\
\hline Unoccupied & & 70 & 57 & 63 & $10 * * \mathrm{i}$ & 41 & $19 *_{i}$ \\
\hline Solitary Play & 70 & & 70 & 73 & $80^{*} p$ & 45 & 46 \\
\hline Onlooker & $77^{*} \mathrm{p}$ & 73 & & 30 & $57^{\circ}$ & 55 & 27 \\
\hline Transition & 43 & $83^{* *} p$ & $20 * \mathrm{i}$ & & 33 & 52 & $15^{* * \mathrm{i}}$ \\
\hline Parallel Play & 27 & $83^{* *} p$ & 53 & $10 * * \mathrm{i}$ & & 31 & 65 \\
\hline Conversation & $3 !$ & 34 & 66 & 48 & 55 & & 35 \\
\hline Group Play & 35 & 42 & 35 & 31 & 42 & 23 & \\
\hline
\end{tabular}

Vore. $\mathrm{p}=$ probable transition; $\mathrm{i}=$ improbable transition.

$n=30$ except for given codes Conversation $(n=29)$ and Group Play $(n=26)$.

${ }^{*} p<.01{ }^{* *} p<.001$.

parallel play (as is the reverse) for both groups. (Transition is also a probable path to solitary play.) Similarities between groups for other shifts between play states can be noted as well. Figure 1 presents diagrams of probable paths for each group.

\section{DISCUSSION}

Despite differences in overall levels of social participation with peers, as evaluated by summary measures. children with and without mild developmental delays appear to exhibit

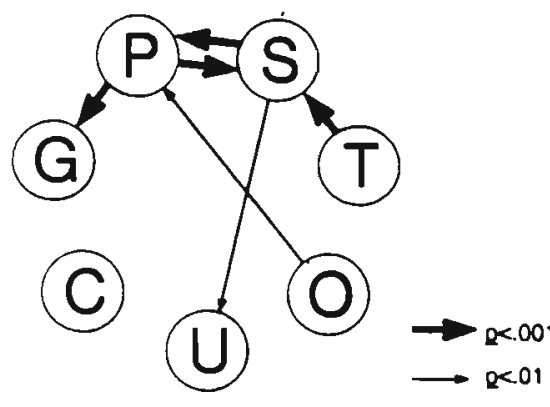

Typically Developing Children

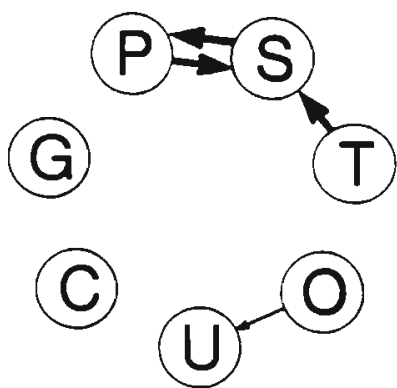

Children with Developmental Delays

Figure 1.

Probable paths between transitions for children with and without developmental delays. 
similar sequential play patterns. Both groups of children. carefully matched on a variety of child and family characteristics. make a similar number of changes from one play state to another. display a similar pattern of remaining in the same play state in adjacent intervals. and present a similar configuration of movements from one play state to another during iree play interactions with their peers. These similarities between children with and without mild developmental delays in sequential play patterns are consistent across inclusive and specialized settings.

That the pattern of social interaction sequences for children with developmental delays is organized over time in a manner similar to that of typically developing children has important implications for intervention. It is not the case that children with developmental delays move haphazardly through play states. On the contrary, probable and improbable paths from one play state to another seem to be guided by a general underlying structure. irrespective of children's developmental status. As a consequence. it is important to capitalize on these fundamental patterns when designing intervention programs. The strategic use of parallel play is a case in point. As Bakeman and Brownlee (1980) have noted. parallel play often serves as a safe transition to group play. Moreover, the solitary-parallel play reciprocity (i.e.. probable paths to each other) permits both the integration of social and object play and a possible shift to solitary play should parallel play fail to yield to group interactions. With this structure already in place. interventions can concentrate on providing children with the tools needed to accomplish social tasks, such as entering a peer group or maintaining play within the free play environment. Both assessment and intervention programs are now being designed within this framework (Guralnick. 1992; Guralnick \& Neville, 1997).

The fact that these patterns are maintained irrespective of whether children are in inclusive or specialized settings further attests to the intrinsic organization of this sequential process. This is a particularly important point for children with developmental delays who participate in inclusive programs. Specifically, the increase in social interactions that usually occurs as a consequence of placement in inclusive preschool settings does not appear to be a fragmented or artificial increment, but rather appears to be integrated within, and linked to. the underlying sequential structure of social participation. This does not mean that children are necessarily more socially competent as a consequence of participation in inclusive settings. as that has not yet been satisfactorily demonstrated (Guralnick. 1990b). Inclusive settings. however, can serve as an effective context for promoting more socially competent interactions. Finally, the fact that the sequential interactions of typically developing children are not disrupted in any way by the presence of children with developmental delays adds to the growing and consistent body of evidence that the social play of typically developing children is not adversely affected by participation in inclusive preschool settings (see Buysse \& Bailey, 1993; Guralnick, et al., 1996).

The playgroup methodology employed in this study has many advantages, including the ability to carefully match children, to eliminate reputational bias, and to allow application of sophisticated recording techniques. The playgroups in this study, however, were only short-term. and future studies need to address the issue as to whether these patterns are maintained over time. Of note, evidence is available for other aspects of peer-related social interactions suggesting that the patterns obtained during playgroups are indeed maintained over time, and similar evidence suggests that findings utilizing the playgroup approach are also robust with regard to type of setting and child characteristics, including gender (Guralnick, in press). Nevertheless, future replications and extensions including different groups of children are needed to determine the generality of findings related to sequential patterns.

Replication also is important to ensure that the absence of differences between groups and across settings obtained in this study is not related to methodological issues. In particular, the relatively low intraclass reliability coeffi- 
cients for some transitions is a concern, although differences were not detected even where values were high. The conservative alpha level must also be considered in the group and setting analyses. The within group patterns, however. (see Figure 1) provide addiional support for the contention that sequential palterns are organized in a similar way for children with and without disabilities. Again. replication with a larger sample size is clearly needed.

Finally, additional work utilizing statistical procedures that go beyond adjacent play states to examine more complex sequential dependencies also will contribute to a better understanding of the organization of children's social play. New mathematical techniques are now being applied to understand the dynamics of social play and regulatory processes (Gottman. Gurainick. Wilson. Swanson. \& Murray, 1997). Yet, the consistency of the results in this apparently initial effort to examine the moment-to-moment sequential play patterns of social participation with peers for children with mild developmental delays suggests both a close correspondence to typically developing children and the existence of an underlying structure that is not disrupted by participation in inclusive settings.

\section{REFERENCES}

Achenbach, T. M., \& Edelbrock. C. (1991). Manual for the Child Behavior Checklist/4-18 and 1991 Profile. Burlington, VT: University of Vermont. Department of Psychiatry.

Bailey. D. B.. Jr.. McWilliam. R. A., Ware. W. B., \& Burchinal, M. A. (1993). Social interactions of toddlers and preschoolers in same-age and mixed- age play groups. Journal of Applied Developmental Psychology, 14, 261-276.

Bakeman. R. (in press). Behavioral observation and coding. In H. T. Rise \& C. K. Judd (Eds.), Handbook of research methods in social psychology. New York: Cambridge University Press.

Bakeman, R., \& Brownlee, J. R. (1980). The strategic use of parallel play: A sequential analysis. Child Development. 51, 873-878.

Bakeman, R., McArthur, D., \& Quera, V. (1996). Detecting group differences in sequential association using sampled permutation: Log odds, kappa, and phi compared. Behavior Re. search Methods, Instruments. \& Computers, 28. 446-457.

Bakeman. R., Quera, V.. McArthur, D.. \& Robinson. B.F. (1997). Detecting sequential palterns and determining their reliability with fallible observers. Psychological Meshods. 2. 357-370.

Barnes. K. E. (1971). Preschool play norms: A replication. Developmental Psichology. 5. 99103.

Buysse. V.. \& Bailey, D. B., Jr. (1993). Behavioral and developmental outcomes in young children with disabilities in integrated and segregated settings: A review of comparative studies. The Joumal of Special Education. 26. 434-461.

Carrow-Woolfolk. E. (1985), Manual for the Test for Auditory Comprehension of Language-Re. vised. Allen. TX: DLM Teaching Resources.

Cohen. J. (1960). A coefficient of agreement for nominal scales. Educational and Psychological Measurement, 20, 37-46.

Coplan. R. J., Rubin. K. H., Fox. N.A.. Calkins. S. D., \& Stewar, S. L. (1994). Being alone. playing alone, and acting alone: Distinguishing among reticence and passive and active solitude in young children. Child Development. 65. 129-137.

Dodge. K. A.. Pettit. G. S., McClaskey. C. L.. \& Brown, M. M. (1986). Social competence in children. Monographs of the Sociery for Research in Child Development, $S I(2$. Serial No. 213).

Doyle. A., Connolly, J., \& Rivest, L. (1980). The effect of playmate familiarity on the social interactions of young children. Child Development, 51, 217-223.

Fox. N. A., Schmidt, L. A., Calkins, S. D., Rubin, K. H., \& Coplan, R. J. (1996). The role of frontal activation in the regulation and dysregulation of social behavior during the preschool years. Development and Psychopathology, 8, 89-102.

Goldman, J. A. (1981). Social participation of preschool children in same versus mixed age groups. Child Development. 52, 644-650.

Gottman, J. M., Guralnick, M. J., Wilson, B., Swanson, C. C., \& Murray, J. D. (1997). What should be the focus of emotion regulation in children? A nonlinear dynamic mathematical model of children's peer interaction in groups. Development and Psychopathology, 9. 421452.

Guralnick. M. J. (1990a). Major accomplishments and future directions in early childhood mainstreaming. Topics in Early Childhood Special Education, 10(2), 1-17.

Guralnick, M. J. (1990b). Peer interactions and the 
development of handicapped children's social and communicative competence. In $\mathrm{H}$. Foot, $\mathrm{M}$. Morgan. \& R. Shute (Eds.), Children helping children (pp. 275-305). Sussex. England: John Wiley \& Sons.

Guralnick. M. J. (1992). A hierarchical model for understanding children's peer-related social competence. In S. L. Odom. S. R. McConnell. \& M. A. Mc Eroy (Eds.). Social competence of voune children with disabilities: Issues and strutegies for interiention (pp. 37-64). Baltimore: Brookes.

Guralnick. M. J. (1997). The peer social networks of young boys with developmental delays. American Journal on Mental Retardation. 101. 595-612.

Guralnick. M. J. (1999). The nature and meaning of social integration for young children with mild developmental delays in inclusive settings. Journal of Early Interiention. 22. 70-86.

Guralnick. M. J.. Connor. R.. \& Hammond. M. (1995). Parent perspectives of peer relations and friendships in integrated and specialized programs. American Journal on Mental Retardation, 99, 457-476.

Guralnick. M. J.. Connor. R.. Hammond. M., Gottman. J.M. \& Kinnish. K. (1996). Immediate effects of mainstreamed settings on the social interactions and social integration of preschool children. American Journal on Mental Retardation. 100, 359-377.

Guralnick. M. J., \& Groom. J. M. (1985). Correlates of peer- related social competence of developmentally delayed preschool children. American Journal of Mental Deficiency, 90. 140-150.

Guralnick. M. J., \& Groom, J. M. (1987). The peer relations of mildly delayed and nonhandicapped preschool children in mainstreamed playgroups. Child Development, 58, 15561572.

Guralnick. M. J., \& Neville, B. (1997). Designing early intervention programs to promote children's social competence: In M.J. Guralnick (Ed.). The effectiveness of early intervention (pp. 579-610). Baltimore: Brookes.

Guralnick, M. J., Paul-Brown, D., Groom, J. M., Booth. C. L.. Hammond, M. A., Tupper. D. B.. \& Gelenter. A. (1998). Conflict resolution patterns of preschool children with and without developmental delays in heterogeneous playgroups. Early Education and Development, 9. 49-77.

Guralnick. M. J., \& Weinhouse. E. M. (1984). Peerrelated social interactions of developmentally delayed young children: Development and characteristics. Developmental Psycholog. 20 $815-827$.

Hollingshead. A. B. (1975). Four factor index of social status. Unpublished manuscript. Yale University. Department of Sociology. New Haren.

Kopp. C. B.. Baker. B. I.. \& Brown. K. W. (1992). Social skills and their correlates: preschoolers with developmental delays. American Joumal on . Mental Retardation. 96. 357-366.

Odom. S. L.. McConnell. S. R.. \& .McEvoy. (Eds.). (1992). Social competence of young children with disabilities: Issues and strategies for interiention. Baltimore: Brookes.

Parker. J. G. \& Asher. S. R. (1087). Peer relations and later personal adjustment: Are low-accepted children at risk? Psychological Bulletin. 102. 357-389.

Parten, M. B. (1932). Social participation among preschool children. Journal of Abnormal Social . Psychology. 27, 243-269.

Roper. R.. \& Hinde. R. A. (1978). Social behavior in a play group: Consistency and complexity. Child Development, 49, 570-579.

Rubin. K. H. (1985). The Play Obseriation Scale (POS) (rev.) Waterloo. Ontario: University of Waterloo.

Rubin. K. H. \& Krasnor. L. R. (1980). Changes in the play behaviours of preschoolers: A shortterm longitudinal investigation. Canadian Journal of Behavioural Science, 12. 278-282.

Rubin. K. H., Lynch. D., Coplan. R.. Rose-Krasnor. L., \& Booth C. L. (1994). "Birds of a feather. .":Behavioral concordances and preferential personal attractions in children. Child Development, 65, 1778-1785.

Rubin, K. H., Maioni, T. L., \& Hornung, M. (1976). Free play behaviors in middle and lower class preschoolers: Parten and Piaget revisited. Child Development, 47, 414-419.

Rubin, K. H., Watson, K. S., \& Jambor, T. W. (1978). Free- play behaviors in preschool and kindergarten children. Child Development, 49. 534-536.

Smith, P. K. (1978). A longitudinal study of social participation in preschool children: Solitary and parallel play reexamined. Developmental Psychology, 14, 517-523.

Sparrow, S. S., Balla. D. A., \& Cicchetti. D. V. (1984). Vineland Adaptive Behavior Scales. Circle Pines, MN: American Guidance Service.

Taylor. A. R., Asher, S. R., \& Williams, G. A. (1987). The social adaptation of mainstreamed mildly retarded children. Child Development. $58,1321-1334$. 
Vandenberg, B. (1981). Environmental and cognitive factors in social play. Journal of Experimental Child Psychology, 31, 169-175.

Wechsler, D. (1989), Wechsler Preschool and Primary Scale of Intelligence-Revised. San Antonio: The Psychological Corporation.

Williams, G. A., \& Asher. S. R. (1992). Assessment of loneliness at school among children with mild mental retardation. American Journal on Mental Retardation. 96, 373-385.

Zimmerman. I. L.. Steiner. V. G.. \& Pond, R. E. (1979). Preschool language scale (rev. ed.). Columbus. OH: Charles E. Merrill.
This research was supported by Grant No. H024K90002 from the Department of Education. Office of Special Education Programs. The authors wish to express their appreciation to Dr. Jim Sack. elt for comments and statistical advice and to an anonymous reviewer for guidance in new analvic sirategies.

Address correspondence to Michael J. Guralnick, Director. Center on Human Development and Disability. University of Washington. Box 357920, Seattle, WA 98195-7920. E-mail: mjgural@u.uashington.edu. 